\title{
Higher Engineering Education for the 21st Century: American Perspective and Its Implications for China
}

\author{
Hongbo Shi* \\ School of Economics and Management, \\ Harbin Institute of Technology at Weihai \\ Weihai, China 264209 \\ hongbo.shi@hotmail.com \\ *Corresponding author
}

\author{
Charles Vest \\ Department of Mechanical Engineering, \\ Massachusetts Institute of Technology \\ Cambridge, USA 02139 \\ cmvest@mit.edu
}

\begin{abstract}
As the multinational companies continue to emerge worldwide, U.S. veteran companies have been challenged. By analyzing the American higher engineering education status and objectives in the 21 st century, that only rely on continuous innovation and business model recreation, firmly grasp the new cutting edge of science and technology, vigorously foster the leading type of engineers, can ensure the U.S. manufacturing sector to revive past glory effectively. In this sense, to China, which has made remarkable achievements in the world, it has both enlightenment and use for reference. Accordingly, countermeasures are given to promote the development of China's higher engineering education.
\end{abstract}

Keywords-globalization; higher engineering education; engineers; technological innovation

\section{INTRODUCTION}

In the early $1960 \mathrm{~s}$ and $70 \mathrm{~s}$, some industrial groups in western European countries rise one after another, such as Unilever, Philips, Siemens, Volkswagen; Followed by the impact from Japanese emerging giants such as Toyota and Sony; Later, rookies in South Korea like Samsung and Hyundai along with Taiwan's electronics companies are also beginning to thrive in succession, which makes American companies constantly challenged. And every time, American firms have found themselves falling into the predicament of the impact because of bosses' off guard. In recent years, some new type of multinational companies have appeared in some developing countries such as Brazil, China, India, Russia, even Egypt and South Africa, those rookies every day have to fight with domestic and western multinationals, under the pressure of competition, they even must struggle to make profit in low price level that are unimaginable to the United States and European countries. Some multinationals in developing countries have already been famous in the world, China's Lenovo Group, for example, in 2005 purchased IBM's personal computer business at the expense of $\$ 11$ billion remarkably; Infosys, Tata Consultancy Services and Wipro (WIT), India's three major manufacturers of software, has become the world's most famous base of computer information technology and have revolutionarily achieved $\$ 650$ billion in annual [1].

What is it that makes these global competitors for those established multinationals? Their primary advantages are: first, they are in the most dynamic places of the world market and possess huge low-cost resource reserves-either production, personnel, engineers, or land, oil and iron ore. In addition, this best combination also includes business innovation, careful management, new technology and process that catering to the trend of global consumption and new products launched faster than those of its competitors.

One nation's rise and fall relies on the development of its productivity, and the development of productivity depends on the talents, and it is education that determines the cultivation of talents. It is a cliché and never needs logical demonstration. Countries with the best engineering talent will take the core status of economic competition and the industrial superiority. In this sense, the United States is in trouble. The competition has brought giant impact to many established companies. Facing the challenges, the United States still has a lot of opportunities. We must have the sense of urgency and need to increase the investment in education, scientific research and innovation. As the main driving force of economy, universities are obligated. And engineering education is an important part of the solution. In fact, since the 1980s, facing the challenge of knowledge-based economy and international competition, the consciousness of American business circle has changed, began to actively get involved in engineering education reform and cultivation of talents of science and technology.

\section{THE STATUS QUO AND THE TARGET OF HigHER ENGINEERING EDUCATION IN THE UNITED STATES}

After the World War II to the 1980s, the scientization trend of American engineering education is becoming more and more serious, which leads to serious disconnect between the quality of university graduates and enterprise needs. In order to strengthen the production-study-research cooperation, starting in 1971, the Federal government has formulated a series of plan, objectively promoting the relationship between the universities and enterprises and mobilized the enthusiasm of enterprises to participate in the engineering education reform [2].

\section{A. New Challenges After Entering the 21st Century}

Throughout the evolution process of science and technology, we found that the theme of the 20th century is physics, electronics, transportation and high-speed communication. While in the 21 st century is: biology, information, energy, water resources and sustainable development. According to the national science foundation (2008) science and engineering indicators data (2000), after 
entering the 21st century, the world's research and development (R\&D) funding has been globalizing. In the entire $\$ 813$ billion (by purchasing power parity-PPP conversion) investment, North America accounted for $\$ 300$ billion, or $36.8 \%$; South America accounted for $\$ 18$ billion, or $2.2 \%$; Europe accounted for $\$ 234$ billion, or $28.7 \%$; Asia accounted for $\$ 246$ billion, or $30.2 \%$; Oceania accounted for $\$ 9$ billion, or $1.3 \%$; and Africa accounted for $\$ 5$ billion, or $0.6 \%$.

On the aspect of R\&D investment, the United States gradually loses the lead from the top. Once upon a time, America was in the lead, especially holding the palm in ratio of R\&D investment to gross domestic product (GDP). From 1986 to 2003, however, America declined in each category of the global share. For example, domestic R\&D investment $-9 \%$ (down 9\%), the United States patent $-2 \%$, SCI papers $-8 \%$, scientific researchers $-8 \%$, a bachelor's degree in S\&E $-10 \%$, Dr New S\&E -30\% [3].

Once upon a time everyone cheered: "we are No. 1!" What about the new cheer? We are No. 15! In the field of high technology and higher education, the United States currently ranks in the world situation as follows (table 1 and figure 1).

\section{TABLE I. THE US CURRENTLY RANKS IN SOME AREAS}

\begin{tabular}{|c|c|c|}
\hline No. & Areas & Ranks \\
\hline 1 & Broadband access & 16 \\
\hline 2 & High school graduation rate & 17 \\
\hline 3 & College graduation rate & 14 \\
\hline 4 & Proportion of college graduates with S\&E degrees & 17 \\
\hline 5 & \%GDP devoted to non-defense research & 22 \\
\hline
\end{tabular}

In addition, only less than $15 \%$ of high school graduates have sufficient mathematical and scientific foundation to be attended to engineering colleges and universities.

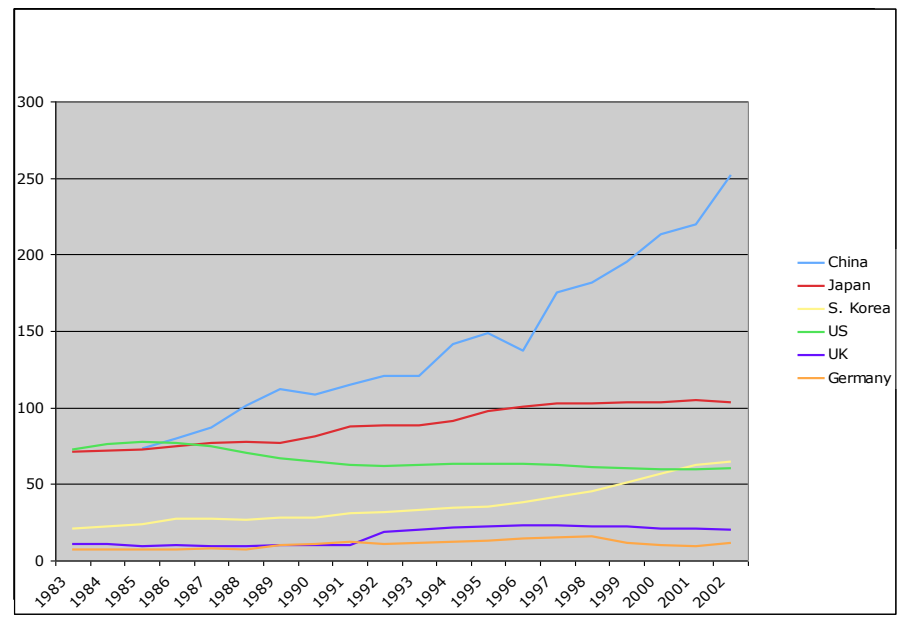

FIGURE I. FIRST ENGINEERING DEGREES (China Rises)

Source: Science and Engineering Indicators 2006, National Science Foundation, Washington, DC

As new competitors join in the world stage, what is our expertise, and where is our advantage? Although not all issues are about numbers, but we know that "the Venture capital is the search for smart engineers." (Freud Kvamme; Kleiner Perkins) Unfortunately, only less than $15 \%$ of American high school graduates have the necessary scientific and mathematical background to consider the application for higher engineering colleges and universities, and at this point, the changing trend of the industry employment proportion from more than 200 years ago also reflected (figure 2).

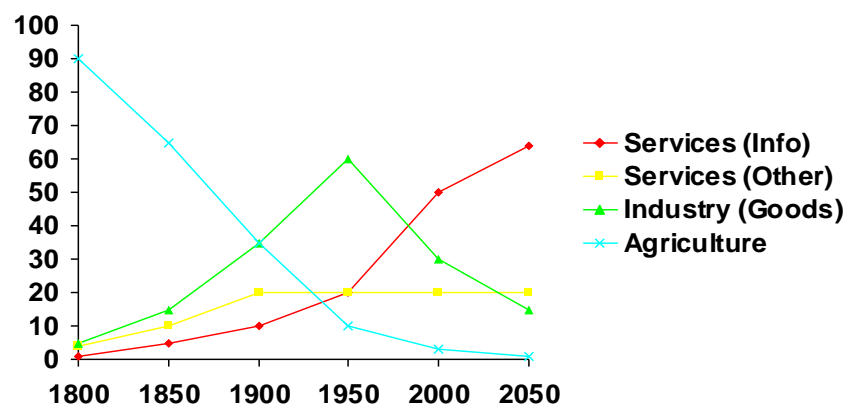

FIGURE II. EMPLOYMENT BY FACTOR: HISTORY AND PROJECTION

Source: Stuart Feldman, IBM Research, Presentation at Carnegie-Mellon University, June 29, 2005

Thomas Friedman pointed out that "the world is flat". In 1989, the Berlin Wall came down; at the same time, Microsoft's Windows went up. With the rapid popularization of Internet, distance and location is no longer a problem. Now we see:

- $\quad \$ 1.5$ trillion worth of fiber connect the world.

- Globalization makes Beijing, Bangalore and Bethesda as the next door neighbor.

- A lot of work, now just click the mouse can be completed in any place.

- New argument: location is important.

- The power of regional innovation cluster.

- Small companies and corporate laboratories and universities in close proximity.

All landowners risk investment network is formed.

There is no doubt that globalization has become an indisputable and inevitable reality.

Another fact should not be neglected is manufacturing migration. From the US to Taiwan, China, to South Korea, and to China (mainland), to Vietnam, later inevitably flow to...Whether can be avoided, the trend has already been very serious.

- From 2000 to 2003, the foreign companies set up 60000 manufacturing factories in China.

- In 2004 chemical companies closed 70 facilities in the U.S. and have tagged 40 more for shutdown.

- 120 major chemical plants are under construction. Only one of them is in the United States, and 50 are in China. 


\section{B. The New Innovation Mode and Corporate Mode}

Innovation is the substantial requirement of the characteristic of the knowledge-based economy era to elite talent. The American university set up innovative talent training system which is the direct embodiment of research universities practicing elite education idea in today's era [4].

Henry Chesbrough, professor in Harvard Business School, put forward the concept of open innovation. Enterprises must integrate the best idea now, no matter where they originated (in other countries, companies, or lab, even in rival organizations). New dynamic business model needs to be in an open, interconnected (authorization, partnership, joint venture) world.

Sam Palmisano, chief executive officer of IBM, pointed out that with the new innovation model a new business model appeared: globally integrated enterprise replaced the multinational companies, leading global technology sharing and the establishment of global IT standards; Implement production shift; Develop a new strategy without borders, form the management and operations for integrated production and value delivery. Manufacturing sector has seen this kind of characteristic, with many modules and countries. For example, according to reports, the new Boeing 787 has 132500 engineering parts produced in 545 locations around the world.

The other two development trends are: small and mediumsized enterprises are to promote employment growth; the importance of small micro enterprises is highlighted.

\section{Engineering Leadership: the Concept and Connotation}

What is a leader? A leader is who takes us to the destination (Bob Galvin). The view of this article: leadership is respect for others and their thoughts; the source of engineering leadership is respect for others, thoughts and objects. Leaders need correct values; engineering leaders need the correct values and technical expertise.

The prosperity of the 21 st century continues along with the pressure of global competition, and work in the field of engineering will find anywhere in the world of knowledge, expertise and innovation. In the face of global competition, the only acceptable response is "dominance". This requires countries to develop all levels of education and training, increase R\&D investment [5]. To lead the future, we must do:

First, inspire a new generation of young people to get ready to solve the practical problems we faced: energy, environment, food, health care, the global service economy, the security of the world. Secondly, to inspire a new generation of young people get ready to aim for cutting-edge engineering science, and devote into these areas.

In the field of engineering, leadership play should be defined like this:

- Play leadership through the project management, technology progress (scientific discovery, technological inventions, technology digestion, absorption and innovation), teaching and innovation.

- Through the engineering practice: management of leadership, entrepreneurial leadership, leadership in social work and political activities, can be inspired by engineering knowledge and thinking process.

- Leadership generated by the project (scientific) knowledge.

\section{THE HighER ENGINEERING EDUCATION INNOVATION: ACTION AND REFLECTION}

The Massachusetts Institute of Technology (MIT), in 1989, published the historic "made in America: the reconstruction of production advantages", and in 1993 put forward "regression (engineering) practice" revolutionary slogans. Engineering practice geared to the needs of globalization, we should integrate science and technology, technical and non-technical, also is projects to true colors, emphasize the practicality, comprehension and innovation of projects.

Engineering education, under the paradigm of engineering, is neither a "restriction to technology" nor "technically narrowed". It is not to see the education plan of science content, humanities, engineering and technical content as separated science education, humanities education, engineering education, or their simple addition, but to regard the content as part of the whole engineering education content, attaches great importance to the combination of analytical unit and comprehensive unit; Emphasis on the education activities being closely in harmony with engineering practice, in a real and complex project environment, aim at the practical need that "modern engineers need to participate in product, process and system life cycle stages of work" to cultivating students [6].

\section{A. The Digital World: Digital Resources in the Field of Education}

In recent years, the recreation of education system has become the mainstream of worldwide engineering education research and practice, and followed the CDIO (Conceive, Design, Implement, Operate) mode, PBL (Project-based Learning) model of engineering education paradigm revolution [7]. In addition, Simulation-based Engineering and Science (SBE\&S) plays an increasingly important role in many fields, at the same time SBE\&S also reflects a huge advantage in improving the engineer practice and innovation ability and expanding scientific understanding [8].

With the popularity of computer and network technology, network infrastructure began to serve for higher engineering education, especially the following successful examples: (1) cheap, unlimited data storage (Inexpensive, Limitless Memory). (2) Digital Archives: commonly used foreign full-text database (JSTOR, ARTstor, Ithaka), the Public Library of Science, Google Library. (3) Platforms/Pedagogy: SAKAI, OKI, Open Learning Initiative at Carnegie Mellon University, Connexion (Rice University), Digital Chemical (UC, Berkeley), Virtual University Enterprises (VUE, Tufts University), Lionshare (Penn State University).

Open teaching content movement is also in full swing. For example, MIT open course ware-1800 free teaching materials of the course is open to anyone all over the world.

In addition, it is the emergence of the concept of "MetaUniversity". What we are observing is a transcendent, accessible, empowering, dynamic, communally-constructed 
framework of open materials and platforms on which much of higher education worldwide can be constructed or enhanced.

\section{B. Training Objectives: Vision and Gap}

I (here refers to Vest) began to work in the higher education field in 1967, by the time we focused on: how to make the fresh full of passion, how to convey what the engineers are actually doing, how to improve students' understanding of a business process, and how to make the students more to think about ethics and social responsibility.

Today, as in 2012, what we focus on still are how to make the fresh full of passion, how to convey what the engineers are actually doing, how to improve students' understanding of a business process and how to make the students more to think about ethics and social responsibility. Moreover, to achieve this goal we must add: (1) Nano - biological - information; (2) Large complex system; (3) The basis of a new life science; (4) Amazing computing and storage capacity; (5) Globalization; (6) Innovation; (7) All landowners leadership; (8) Teamwork across disciplines, fields, nations and cultures; (9) Experiential Learning: Conceive / Design / Implement / Operate (CDIO); (10) Entrepreneurship; (11) Product development and manufacturing; (12) Sustainable development [9].

Our graduates must be engineers under the background of globalization: skilled, knowledgeable, mastering a variety of strong sense of language, culture, innovation and entrepreneurial skills, understanding the world market, having business savvy, flexible and easy to change career. This is quite consistent with other emerging views, such as the American academy of engineering college graduates training objectives defined below (cultivate 2020 engineers): master technology, broad education, as a global citizen consciousness, can become the leading business and public services, ethical and moral foundation.

TABLE II.

THE US GRADUATES COMPETENCES TODAY

\begin{tabular}{|c|c|c|c|}
\hline No. & Contents & Ideal & Real \\
\hline 1 & Technically adept & $\sqrt{ }$ & $\sqrt{ }$ \\
\hline 2 & Broadly knowledgeable & $\sqrt{ }$ & $<$ \\
\hline 3 & Innovative and entrepreneurial & $\sqrt{ }$ & $<=$ \\
\hline 4 & Commercially savvy (especially US) & $\sqrt{ }$ & $<$ \\
\hline 5 & Multilingual (except US) & $\sqrt{ }$ & $\sqrt{ }$ \\
\hline 6 & Culturally aware & $\sqrt{ }$ & $<=$ \\
\hline 7 & Able to understand world markets & $\sqrt{ }$ & $<$ \\
\hline 8 & Professionally flexible and mobile (probably) & $\sqrt{ }$ & $\sqrt{ }$ \\
\hline
\end{tabular}

China's Former President $\mathrm{Hu}$ Jintao put forward such vision on prospective scientists and engineers (at the Chinese academy of sciences, Chinese academy of engineering in both Houses of Congress's speech, on June 5, 2006): The ambition of having both ability and political integrity, the courage to pursue truth, strict and scientific thinking and solid professional knowledge and international vision, strong team spirit, honesty and serious working attitude, and the ability to lead the innovation team [10].
How do we do? In general, graduates in the United States today are probably at this level (table 2):

\section{Other Views: a Review and Reflection}

Here are personal views on some related problems.

- What is important in engineering education?

Strive to make the university and college of engineering more exciting, creative, strict and demanding, and full of adventure and build the atmosphere fully authorized... All of these are more important than detailed lesson plans, which is also the Massachusetts Institute of Technology experience.

- The need of teaching research and evaluation.

Our investment in research and development of industry, at best, is only a fraction of its budget on the core business. Teachers should be better in defining education targets, and measuring the progress in the process of achieving those goals. The good news is that currently movement has been in this direction.

- There is a lot of engineering/technical education innovation, including:

Experiential learning, Project plans, Computer-assisted learning, CDIO, Business plan competitions, Undergraduate research opportunities program (UROP), Undergraduate practice oriented plan (UPOP), Studio learning, Web lab, the "Second life"... And so on.

- New engineering schools, such as:

Olin College of Engineering, New American University, Arizona... But we do not have to propagate them.

\section{THE ENLIGHTENMENTS TO CHINA OF HIGHER} ENGINEERING EDUCATION INNOVATIONS IN THE US

The status of a state in the 21 st century depends on the ratio of innovative talents to the population in the country. A new round of International economic competition has brought great challenge to China's education. Good experience in foreign countries as a reference at the same time, what needs to take the initiative is to explore suitable training mode for engineering science and technology talent considering China's national conditions. In recent years, under Zhu Qingshi's administration the Southern University of Science and Technology has struggled forwards a way and explored the example fully. It shows that China's higher education reform to a substantive breakthrough must follow the path: first is the innovation of concept, and then the system innovation, the education innovation is the last.

\section{A. Adjusting the Training Objectives of Higher Engineering Education}

Quite some time in the past, our country's higher education following the Soviet model, pay attention to the training of specialists in the field of "tools" to meet the needs of social and economic development. After reform and opening up, the "tools" type gradually could not adapt to diversification trend of talents and social needs. Famous "question of Qian Xuesen" revealed that currently what China lacks most is the high quality of top creative talents [11]. The national medium and 
long-term education reform and development plan outline (2010-2020) established the center position of the talent training in the work of colleges and universities, which focus on cultivating knowledgeable and reliable high-quality talents with ability and top creative talent [12]. In the higher engineering education in the United States, They pursue students' basic quality of excellence, and all kinds of knowledge and ability conducive to the migration. About the "excellence" for the standard has important guiding significance to the innovation education in university of engineering [13]. For the implementation of the "outstanding engineers training plan", our country's engineering universities must continuously strengthen the popularization of general education and innovation education.

\section{B. In View of the Existing Problems to Promote the Innovative Education}

At present, the problems and disadvantages existing in the field of higher engineering education include: (1) Concept of education needs to change as soon as possible, the teacher should consider more concerned about the "education" and less about "choosing and employing persons"; (2) In terms of curriculum system, there is also the phenomenon that to set up lessons due to people, leading to the result that the course content can not timely reflect the frontier disciplines theory and method; (3) Teaching mode is more traditional "tells", which is not conducive to mobilize students' learning initiative and enthusiasm and is also not conducive to cultivate students' innovative spirit; (4) In the evaluation of training quality, the main issue is paying attention to the evaluation on students' ability of mastering knowledge, lack of evaluation on students' innovation ability of solving practical problems. Promoting the innovation education in engineering university is the implementation of "innovation driven development" strategy put forward by the big major moves by the Central 18th Plenary Congress, which also is the objective requirement to adapt to speed up the transformation of economic development patterns. American experience suggests that university should not only cultivate the students' engineering professional knowledge, professional skills and basic quality; more importantly is to improve the students' ability of organization, leadership, which makes the students have innovation consciousness and team spirit.

\section{The Innovative Pattern and Countermeasures to Realize the Goals}

Many universities in our country, especially in higher engineering colleges and universities have put forward a slogan "production-teaching-research combination". The background of the slogan put forward is that education must highly adapt to the requirement of economy and think positively: how to transform knowledge created by university into social productivity and economic benefits better and faster [14]. On the other hand, our national enterprises have clearly recognized that if education cannot provide high quality talent resources, the basis of enterprise' survival and development will be wiped out. Therefore, we should gradually found joint training mechanisms joined by colleges, universities, research institutes, industries, as well as enterprises, and push forward the integrated engineering training "bi-tutorial system" mode. The implementation of "the graduate student education innovation plan" is also on the agenda. For the industry, in addition to more spending in higher engineering education, they also should put the engineering profession's emphasis on product design, product development and innovation, and enhance the status of engineers on the value chain [15]. For engineering universities, they should make full use of university-enterprise cooperation platform, and constantly improve the quality of talent training, which can provide intellectual safeguard and support for economic and social development.

\section{ACKNOWLEDGMENT}

Sponsored by Ministry of Education: "humanities and social sciences research project special task (engineering science and technology talent training research)" (13JDGC014).

\section{REFERENCES}

[1] F. Luthans, J. P. Doh. International management: culture, strategy and behavior [M]. McGraw Hill Companies, 2009.

[2] Jiangxia Li. Actively advocate, active participation, deepen cooperation, fully assist - the role US corporate play in engineering education reform [J]. Journal of Higher Engineering Education Research, 2012, (2): 121126.

[3] C. M. Vest. The context and challenge for 21 st century engineering education [J]. Journal of Engineering Education, 2008, (7).

[4] Guanqun Shi, etc. Entrepreneurial innovation, entrepreneurship education and entrepreneurial university network building - take Stanford University for example [J]. Journal of Foreign Education Research, 2009, (6) : 79-79.

[5] C. M. Vest. First-class university, the outstanding principal [M]. Jinsong Lan translated. Beijing: Peking University Press, 2008.

[6] Min Ye. A basic study on American engineering education evolution [J]. Journal of Higher Engineering Education Research, 2013, (2) : 109-114.

[7] E. F. Crawley, etc. Reconsidering engineering education from the international CDIO cultivating mode and methods [M]. Peihua Gu et al. Beijing: Higher Education Press, 2012.

[8] Xiaodong Zou, etc. Modeling and simulation: innovation of engineering and scientific talents cultivating mode [J]. Journal of Higher Engineering Education Research, 2013, (3) : 32-37.

[9] R. Dodds, R. Venables. Engineering for sustainable development: guiding principles $[\mathrm{M}]$. The Royal Academy of Engineering, London, 2005 .

[10] $\mathrm{Hu}$ Jintao. $\mathrm{Hu}$ on the 13th of the Chinese academy of sciences academician assembly and academician of Chinese academy of engineering eighth conference speech [N]. Harbin Daily, 2006-06-06.

[11] Qixin Xi. The biography of Qian xuesen [M]. Beijing: People's Press, 2011

[12] The State Council. The national medium and long-term education reform and development plan (2010-2020) [M]. Beijing: China Legal Press, 2010.

[13] Lijun Liu, etc. The US first-class universities' entrepreneurship education and the cultivation of innovative entrepreneurial talents in China [J]. Journal of China Higher Education Research, 2009, (5) : 50 $51,67$.

[14] Zhongming Jin, etc. Night talk in Hengshan: arguing the 50 educational problems [M]. Shanghai: East China Normal University Press, 2000.

[15] Manli Li. A new probe into engineers and engineering education [M]. Beijing: The Commercial Press, 2010. 